\title{
Dijital Çağda Afet Yönetimi: Dijital Bölünme Perspektifinden Bir İnceleme
}

\author{
Nur Sinem PARTiGÖç ${ }^{1}$ ve Çiğdem TARHAN ${ }^{2}$
}

Öz

Günümüzde bilgi ve iletişim teknolojileri (BIT) hızla yaygınlaşmakta ve toplumun her kesimini her konuda etkisi altına almaktadır. Genel biçimiyle teknolojinin yararlarından faydalananlar ile faydalanmayanlar arasındaki uçurum olarak ifade edilen dijital (sayısal) bölünme kavramı, farklı koşullara sahip kişilerin, bilgi ve iletişim teknolojilerine erişim imkânı ile internet kullanım amaçlarına yönelik geniş bir konuyu kapsamaktadır. Kentsel alanlarda afet yönetimi alanında yapılan çalışmalar da bu kapsama dâhil edilmektedir. Pek çok faktörün ve disiplinin etkisinde şekillenen afet yönetimi alanında ülkemizde çeşitli projeler geliştirilmiştir. Ancak ulusal ve kentsel ölçekte yapılan çalışmaların afet durumunda kullanıcılara ulaşması konusunda sorunlar yaşanmaktadır. Çalışmada temel amaç, ülkemizde kentlerin afet konusundaki kırılganlığı ve hassasiyeti göz önünde bulundurularak yapılan BiT tabanlı uygulamaların daha çok kullanıcıya ulaşmamasının nedenlerinin irdelenmesi ve farklı eşitsizlikler nedeniyle gözlenen dijital uçurumun giderilmesi amacıyla politikalar üretilmesidir. Akademik yazın ve güncel uygulamalara yönelik yapılan araştırmalar kapsamında BIT tabanlı uygulamaların afet yönetiminde doğru ve etkin kullanılmasına yönelik çözüm önerileri ve politikalar üzerinde durulmuştur.

Anahtar Kelimeler: Dijital bölünme, BiT, Eşitsizlik, Afet planlama, Kentsel kırılganlık.

\section{Disaster Management in the Digital Age: A Review from Digital Divide Perspective}

\begin{abstract}
\footnotetext{
${ }^{1}$ Şehir ve Bölge Planlama Bölümü, Pamukkale Üniversitesi, Denizli

2 Yönetim Bilişim Sistemleri Bölümü, Dokuz Eylül Üniversitesi, İzmir

*ilgili yazar / Corresponding author: spartigoc@gmail.com

Nowadays, information and communication technologies (ICT) are spreading rapidly and taking every part of the society under influence. The digital divide can be defined as the gap between those who benefit from the benefits of digital technology and those who cannot. It encompasses a wide range of individuals who are different in terms of socio-economic and geographical conditions, access to information and communication technologies, and the use of the Internet. In this context, there exist various studies related the disaster planning in urban areas. Various projects have been developed in our country in order to transfer spatial data to digital environment and to use it effectively in case of disaster by the authorities and citizens. However, there are problems in national and urban scale studies to reach the users in case of disaster. The main purpose of the study is to examine the reasons why the ICTbased applications are not reached to the users by considering the fragility and sensitivity of our cities in terms of disaster and to produce policies to eliminate the digital gap observed due to different inequalities. As part of comprehensive research in the academic literature and current applications, effective solutions proposals and also policies have been 
developed in terms of the usage of ICT-based applications in the disaster management correctly and efficiently.

Keywords: Digital divide, ICT, Inequality, Disaster planning, Urban vulnerability.

\section{GíRiş}

Sosyal gruplar arasında bilgi paylaşımı için bloglar, sohbet odaları, wiki'ler, Facebook, Twitter, Flickr, Linkedln ve YouTube Kanalları gibi sosyal medya kullanımında bir artış görülmektedir (Gülaslan, 2018; Elbaşı, 2015). Sosyal medya verilerinin, afet yönetimi alanında ortaya çıkan vakalarda bilgi toplamak ve doğrulamak amacıyla giderek daha fazla kullanılı̆̆ı gözlenmektedir (URL1, 2019; Uluğ, 2009). Sosyal medyaya yalnızca vakalara ilişkin güncel verilerin toplanması amacıyla başvurulmamakta; aynı zamanda afet etkisinin "büyük resmi" hakkında durumsal farkındalık oluşturmak için tehlike olayı, yardım ve geri kazanımla ilgili kritik bilgilerin kamuya yayılması için yaygın biçimde tercih edildiği gözlenmektedir. Afet sırasında ve sonrasında özellikle kentsel nitelikli alanlarda bazı bölgeler daha ağır hasar aldığı ve can ve mal kayıplarının sayısı oldukça fazla olduğu için bu bölgelerde sosyal medya verilerinden elde edilen durumsal farkındalık bilgisi önyargılı olabilir. Afet yönetimi gelecek vaat eden bir kanal olarak popülerlik kazansa da, sosyal medya verilerinin kullanımındaki sosyal eşitsizlik, bu tip araçların kullanımı konusunda temkinli hale gelinmesine neden olmaktadır. Bilgi ve iletişim teknolojilerine erişimi olan ve olmayan gruplar arasındaki boşluğa atıfta bulunan "dijital bölünme" kavramı (van Dijk, 2006) bazı dezavantajlı grupların (düşük gelirli, düşük eğitimli, yaşlı, vb.) bu araçlardan yoksun olabileceğine ve dolayısıyla sosyal medya aracılığıyla bilgi paylaşımından mahrum kalabileceğine odaklanmaktadır.

Ulusal ve kentsel ölçekte yapılan çalışmaların (kurumsal, akademik, proje bazında, vb.) afet durumunda kullanıcılara ulaşması konusunda sorunlar yaşanmaktadır. Vatandaşların ikamet ettiği kentsel bölgedeki afet toplanma alanının varlığından haberdar olmaması, afet sonrasında konutuna veya işyerine en yakın konumda toplanma alanının lokasyonunu bilmemesi gibi sorunlar bilgi ve iletişim teknolojilerinden (BIT) yeterince yaranılmadığının temel göstergelerindendir (Yaman ve Çakır, 2017). İşte bu noktadan hareketle, çalışmada temel amaç, ülkemizde kentlerin afet konusundaki kırılganlığı ve hassasiyeti göz önünde bulundurularak yapılan BIT tabanlı uygulamaların daha çok kullanıcıya ulaşmamasının nedenlerinin irdelenmesi ve farklı eşitsizlikler nedeniyle gözlenen dijital uçurumun giderilmesi amacıyla politikalar üretilmesi olarak belirlenmiştir.

\subsection{Bilginin Gerçek Zamanlı Olarak Dağıtılması}

Geleneksel olarak, kriz ve risk iletişimi, radyo ve televizyon gibi kitle iletişim araçlarına büyük ölçüde dayanmaktadır. Son yıllarda sosyal medya, bilginin yayılması için önemli bir kaynak olarak ortaya çıkmıştır. Geleneksel kitle iletişim araçlarının tek yönlü iletişimiyle karşılaştırıldığında, sosyal medya geleneksel gönderen / alıcı modelini bozmaktadır. Sosyal medya kullanıcıları hem mesaj alabilir hem de mesaj gönderebilir. Mesleki haber muhabirlerinin durumu bildirmek için sahaya gelmesini beklemek yerine, bireyler ilk elden bilgi toplayabilir ve bunu gerçek zamanlı olarak sosyal medya aracılığıyla yayabilir. Mesajlar, kullanıcıların sosyal ağları üzerinden sosyal medya kanalları üzerinden birçok kişiye hızlı bir şekilde iletilebilir. Bu noktadan hareketle, denilebilir ki, sosyal medya sahip olduğu geniş etki alanıyla geleneksel kitle iletişim araçlarından önemli ölçüde farkılaşmaktadır. Sosyal ağlar aracılığıyla edinilen iletişim ve etkileşim olanakları, yalnızca bireysel iletişimi devam ettirmek amacına değil, aynı zamanda toplum üzerinde bir tür kontrol mekanizması kurulabilmesi amacına da hizmet etmektedir. 


\subsection{Durumsal Farkındalık Oluşturmak}

Durumsal bilgi üretimi, kullanıcıların sosyal medya bilgilerinin kullanımı konusunda bilinçli olup olmadıklarına bağlı olarak aktif veya pasif olabilir. Aktif bilgi üretimi, sosyal medya kullanıcılarının olayları aktif olarak bildirdiğini ya da yardım kuruluşlarının acil vakalara derhal yanıt verebilmeleri umuduyla yardım isteyen anlamına gelir. Pasif bilgi üretimi, sosyal yardım kuruluşlarından aktif olarak yanıt isteyen veya talep eden kullanıcılar olmadan durumsal farkındalık oluşturmak için mevcut sosyal medya verilerinin veri madenciliği anlamına gelir.

\section{SOSYAL MEDYA BILGILERINNIN GÜVENILIRLIĞi}

Her ne kadar sosyal medya, afet yönetimi için risk iletişimini ve bilgi dağıtımını iyileştirme konusunda büyük potansiyele sahip olsa da, sosyal medya kaynaklarından elde edilen bilgilerin kalitesinin güvenilirliği ile ilgili bazı endişeler mevcuttur (Goodchild ve Glennon 2010; Goodchild ve Li 2012). Bu endişelerin birincisi bilginin doğruluğudur. Her ne kadar sosyal medyadan gelen bilgiler genel olarak doğru olsa da, sosyal medya tarafından yayılan yanlış veya güncel olmayan bilgilerin oluşma intimali vardır. Sosyal medya kaynaklarından elde edilen bilgilerin kalitesinin güvenilirliği ile ilgili endişelerden ikincisi, sosyal medyanın kötü amaçıı kullanımıdır. Sosyal medya, şakalar veya terör saldırıları için kötüye kullanılabilir. Sahte yardım çağrıları, gerçek acil olmayan yerlerden sosyal medya sitelerine girilebilir. Nefret grupları ilk saldırıyı yaratabilir ve daha sonra bölgeye ilk müdahale edenleri çekmek ve onlara ikincil bir saldırıda zarar vermek için yardım çağrısı yapmak için sosyal medyayı kullanabilir. Sosyal medya kaynaklarından elde edilen bilgilerin kalitesinin güvenilirliği ile ilgili endişelerden üçüncüsü, veri üretiminde önyargıdır. Sosyal medya verilerinden oluşturulan durumsal farkındalığa tam olarak güvenebilmemiz için, veri üretiminde önyargılar olup olmadığını sormamız gerekir.

Araştırmalar sosyal medyaya katılımın sosyal gruplar arasında, mekan ve zaman içerisinde eşit olmadığını göstermiştir. Bilgilerin sosyal medya aracılığıyla doğrudan ve dolaylı olarak nasıl dağıtıldığını açıklamak için sosyal aracılı kriz iletişimi (SMCC) modelini kullanmıştır. Kolaylık ve kişisel katılımın yanı sıra kişisel tavsiyeler gibi üçüncü taraf etkisinin sosyal medya kullanımını desteklediği saptanmıştır. Ayrıca, sosyal medya kullanımındaki mekânsal ve zamansal heterojenliğin incelendiği çalışmalar da mevcuttur. Flickr kullanıcıları hafta sonları daha aktifken farklı saat dilimlerinin sosyal medya kullanımı konusunda çeşitlilik gösterdiği saptanmıştır. Ayrıca, sosyal medya verilerinin yerleri ile yerel halkın sosyoekonomik özellikleri arasındaki ilişkileri de araştırılmıştır. Buna göre, iyi eğitimli insanların yönetim, işletme, bilim ve sanat mesleklerinde, coğrafi referanslı tweet ve fotoğrafların oluşumunda yer almasının daha muhtemel olduğu tespit edilmiştir.

\section{DİJITAL BÖLÜNME}

1950'li yıllardan günümüze kadar geçen sürede elektronik ve haberleşme alanında meydana gelen yenilikler ve gelişmeler sayesinde, bilgiye erişim olanakları artmış ve toplumun farklı kesimleri arasında bu olanaklar bakımından farklılıklar önemli ölçüde azalmıştır. Bu gelişmelere bağlı olarak BIT yaygınlaşmıştır. İnternetin günlük yaşamımızda her geçen gün daha fazla yer ediniyor olması, bu teknoloji türlerinin kullanımında gözle görülür bir artışa vesile olmakta ve hem toplumsal hem de ekonomik bakımlardan köklü değişimlere yol açmaktadır. Olumlu ve yenilikçi özelliklerinin yanı sıra, bireysel ve toplumsal ölçekte farklılaşan niteliklere (yaş, cinsiyet, gelir düzeyi, eğitim düzeyi, vb.) bağlı olarak teknolojik olanaklara erişim konusunda bazı eşitsizlikler yaşandığı gözlenmektedir. Bu eşitsizliklerin temelini oluşturduğu kavram olan dijital (sayısal) bölünme, genel olarak tanımlanırsa, şirketler veya ülkeler arasındaki BiT'e erişim ve bu teknolojilerin kullanım farklılıklarını ifade 
etmektedir (URL2, 2019). 1990'lı yıllardan bugüne yaygınlaşan internet kullanımı sayesinde giderek popüler hale gelen dijital bölünme kavramı zaman içinde özellikle gelişmiş ülkeler arasındaki erişim ve kullanım farklılıklarını kapsayacak biçimde de kullanılmaya başlanmıştır (James, 2005; Gürcan, 2015).

Genel haliyle, dijital bölünme üç alt başlıkta ele alınmaktadır. Bunlar erişim uçurumu (access divide), kullanım uçurumu (usage divide) ve yetenek uçurumudur (skills divide) (Korea Agency, 2004). "Erken dönem dijital bölünme" olarak ifade edilen erişim uçurumu kavramı, BiT ürün ve hizmetlerine erişim olanağı olan ve olmayan bireyler veya gruplar arasındaki farklılıkları ifade etmek için kullanılmaktadır. Her ne kadar dünya genelinde kamu eliyle BiT ile ilişkili yatıımlara ağırlık verilmesi sonucunda bu farklılıklar önemli ölçüde azaltılmış olsa da, yatırımların özel sektör eliyle yapıldığı ülkelerde bu eşitsizlik halinin halen devam ettiği görülmektedir. Diğer bölünme türü olan kullanım uçurumu kavramı, BíT ürün ve hizmetlerini kullanabilen ve kullanamayan bireyler veya gruplar arasındaki farklılıkları ifade etmek için kullanılmaktadır. BiT kullanımının artııııması amacıyla farklı ülkelerde yapılan uygulamalar (temel BIT becerileri eğitiminin pek çok ülkede ilköğretim seviyesine çekilmesi, BiT destekli eğitim uygulamaları ve BiT kullanımının pek çok şirket için işe alım şartı haline gelmesi, vb.) kullanım uçurumunun azaltılması için kritik adımlardır. Son olarak, eğitim olanaklarının farklılıklarından kaynaklanan yetenek uçurumu kavramı, BiT alanında eşitsizliklerin ve farklılıkların giderilebilmesi için uzun süre ve emek gerektiren dijital bölünme türüdür. Eğitim sisteminden altyap s sistemine kadar pek çok alanda orta ve uzun vadede strateji ve eylemler geliştirilmesi gerekmektedir (OECD, 2001; James, 2005; Gürcan, 2015).

\section{AFET YÖNETIMINDE BILGI VE ILETIŞiM TEKNOLOJILERININ ROLÜ}

Afet yönetiminde dirençlilik bireysel ve çevresel faktörlerle yakından ilişkilidir. Direnç kavramı Varol ve Kaya (2018) tarafından üç farklı katman ile tanımlanmıştır. Çekirdek direnç, zaman içinde nispeten statik kalmış olan ve bireyin psikolojik, fiziksel özelliklerine ve cinsiyetine dayanan fizyolojik temeline odaklanır. İçsel direnç, bireyin bireysel özellikleri ve ailevi özellikleri, arkadaş çevresi, eğitim durumu ve sosyal çevresi ile ilişkilerine dayanan direncini temsil eder. Dışsal direnç ise bulunduğu ortamın çevresel coğrafik özellikleri, sosyoekonomik durumu, kurumların ve altyapıların durumu, ulaşım vb. gibi birçok dış etkene bağlı olarak gelişen direnci temsil eder (Varol ve Kaya, 2018). Bu kavramlardan yola çıkarak, toplumun afetlere karşı direncinin bireysel özelliklerinden başlayarak, yaşadığı ortam özelliklerine kadar genişleyen birçok faktörün ve disiplinin etkisinde şekillendiği ifade edilebilir.

Bir toplumun ya da bireyin afetlere karşı dirençliliği ne kadar fazla ise ve kırılganlığı az ise; afetlerle başa çıkabilme kapasitesi o oranda yüksektir. Afet zararlarının azaltılması amacıyla afet yönetimi aşamalarında yapılması gereken faaliyetlerin planlanması ve farklı paydaşların dâhil olduğu etkin bir afet yönetim süreci sağlanabilmesi adına bilgi teknolojilerinin sıklıkla tercih edildiği ve önemli avantajlar sağladığı bilinmektedir. OECD üyesi ülkelerin afet yönetiminde dijital eşitsizliği gidermeye çalışırken izlediği politikalar şu şekilde sıralanabilir (Kılıç, 2011): bireylere, hanelere ve iş yerlerine teknolojinin yaygınlaştırılması, Devletin geliştirme ve uygulama projelerinin başlatılması, eğitim ve öğretim girişimlerinin başlatılması, uluslararası işbirliği oluşturulması olarak gruplandırılmaktadır. Afet yönetiminde BíT ürün ve hizmetlerinin etkin biçimde kullanılabilmesi adına ülkemizde çeşitli projeler geliştirilmiştir (AYDES, Radius, TAMP, vb.). Ancak ulusal ve kentsel ölçekte yapılan çalışmaların afet durumunda kullanıcılara ulaşması konusunda sorunlar yaşanmaktadır. Vatandaşların ikamet ettiği kentsel bölgedeki afet toplanma alanının varlığından haberdar olmaması, afet sonrasında konutuna veya işyerine en yakın konumda toplanma alanının lokasyonunu bilmemesi gibi sorunlar BîT'ten yeterince yaranılmadığının temel göstergelerinden bazılarıdır. 


\section{SONUÇ}

Teknolojik altyapının yetersiz olması, afet esnasında ve sonrasında afete maruz kalan bölgede yaşanan teknik aksaklıklar, sosyal medya kullanımı konusunda yeterli bilgi sahibi olunmaması gibi sebeplere bağlı olarak afet durumunda BiT ürün ve hizmetlerinin etkin biçimde kullanılması mümkün olamamaktadır. Bu tip durumlarda vatandaşları doğru bircimde yönlendirebilmek adına kurum ve kuruluşlar tarafından çeşitli çalışmalar yapılmaktadır. 2012 yılında yaşanan, Amerika ve Kanada'yı ciddi şekilde etkileyen Sandy Kasırgası sırasında sosyal medyaya yayılan pek çok asılsız haber ve söylentiyi kontrol altına alarak yayılmasının engellenmesi bu çalışmalara örnek verilebilir (Çalışkan ve Mencik, 2015). İstanbul İli Beylükdüzü İlçesi özelinde yerel yönetim tarafından hazırlanan ABIS (Afet Bilgi Sistemi) uygulamasıyla vatandaşların afet sırasında ve sonrasında toplanabileceği alanların konum bilgilerine kolaylıkla ulaşabilmelerinin sağlanması ise bu kapsamda yapılan çalışmalara örnek verilebilir.

Eskiye kıyasla, artık tam zamanlı biçimde yaşantımıza giren bilgi ve iletişim teknolojileri afet yönetiminde pek çok bakımdan önemli avantajlar sağlamasının yanı sıra, doğru ve etkin biçimde kullanılmadığı durumlarda hem yetkililer hem vatandaşlar hem de sosyal medya kullanıcıları için dezavanjlı durumlara neden olabilir. Bilgi akışının kontrol edilememesi, asılsız haber ve söylentilerin hızlıca geniş kitlelere yayılması, elde edilen bilginin yanlış yorumlanması, vatandaşlara hızlı geri dönüşler yapılmaması gibi yeni krizler yaratabilecek durumlar örnek verilebilir (Sayımer, 2008). Afetler, her ne kadar kısa süreli ve belirli coğrafyalarda gerçekleşiyor olsa da, etkileri uzun süreli ve büyük ölçekte yaşanmaktadır. Son dönemlerde pek çok platformda afet öncesinde alınacak önlemlerin afet sonrasında yapılacak müdahale ve iyileştirme çalışmalardan çok daha önemli olduğu ifade edilmektedir. Bu kapsamda, teknolojinin sunduğu olanaklardan afet yönetiminde yararlanabilmek adına gerekli ve yeterli teknolojik altyapının hazırlanması, ilgili kurum ve kuruluşların bilinçlendirilmesi, vatandaşlara afet sırasında ve sonrasında sosyal medyanın kullanımı üzerine eğitimler verilmesi ve yönlendirmeler yapılması, sosyal medyanın daha etkin biçimde kullanılabilmesi adına çeşitli kampanyalar düzenlenmesi gibi çalışmalar yapılmasının olası can ve mal kayıplarının azaltılması açısından hayati önem taşıdığı unutulmamalıdır.

\section{Kaynaklar}

Çalışkan, M., Mencik, Y. (2015). Değişen Dünyanın Yeni Yüzü: Sosyal Medya, Akademik Bakış Dergisi, 50, $254-277$.

Elbaşı Yılmaz, G. (2015). Sosyal Medyada Pazarlama: Sosyal Medyada Kullanıcı Motivasyonunun Üniversite Öğrencilerinin Sosyal Medya Pazarlama Algısına Iliş̧kin Bir Uygulama. (Yayımlanmamış yüksek lisans tezi). İstanbul Ticaret Üniversitesi, Sosyal Bilimler Enstitüsü, İşletme, İstanbul.

Goodchild, M.F., Glennon, J.A. (2010). Crowdsourcing geographic information for disaster response: a research frontier. Journal International Journal of Digital Earth, Volume 3, Issue:3, Pages: 231-241.

Goodchild, M.F., Li, L. (2012). Assuring the quality of volunteered geographic information. Spatial Statistics, Volume 1, May 2012, Pages 110-120.

Gülaslan, T. (2018). Kamu Yönetiminde Sosyal Medya Kullanımı ve Yönetimi: Temel İlkeler ve Öneriler. (Yayımlanmamış doktora tezi). Hacettepe Üniversitesi Sosyal Bilimler Enstitüsü, Siyaset Bilimi ve Kamu Yönetimi Anabilim Dalı, Kamu Yönetimi Doktora Programı, Ankara. 
Gürcan, F. (2015). Türkiye'de ve Dünyada Sayısal Bölünme. Uzmanlık Tezi, Kalkınma Bakanlığı, Bilgi Toplumu Dairesi Başkanlığı, Ankara.

James, J. (2005). The global digital divide in the Internet: developed countries constructs and Third World realities. Journal of Information Science, 31 (2), pp. 114 - 123.

Kılıç, Ç. (2011). Küreselleşen Dünyada Dijital Bölünme Sorunu. Erzincan Eğitim Fakültesi Dergisi. Cilt-Sayı: 13-1, Sayfa: 81-91.

Korea Agency (2004). How to measure the digital divide, Korea Agency For Digital Opportunity and Promotion.

OECD (2001). Understanding the Digital Divide, Paris. https://doi.org/10.1787/236405667766.

Sayımer, İ. (2008). Sanal Ortamda Halkla İlişkiler, 1. Baskı, Beta Yayınları, İstanbul.

Uluğ, A. (2009). Nasıl Bir Afet Yönetimi? İzmir Kent Sempozyumu Bildiriler Kitabı. Erişim adresi: https://www.tmmob.org.tr/sites/default/files/dc4876f3f08201c_ek.pdf.

URL 1 (2019). Sosyal Medya ve Afet. Erişim Adresi: https://www.acilci.net/sosyal-medya-veafet/, Erişim tarihi: 01.02.2019.

URL 2 (2019). Bilgi Toplumu. Erişim Adresi: https://www.bilgitoplumu.gov.tr/, Erişim tarihi: 01.02.2019.

van Dijk, J. (2006). Digital divide research, achievements and shortcomings. Poetics, Volume 34, Issues 4-5, Pages 221-235.

Varol, N. ve Kaya, Ç.M. (2018). Afet Risk Yönetiminde Transdisipliner Yaklaşım. Afet ve Risk Dergisi. 1(1), Sayfa: 1-8.

Yaman M. ve Çakır, E. (2018). Dijitalleşen Dünyada Akıllı Afet ve Acil Durum Uygulamaları. Insan ve Toplum Bilimleri Araştırma Dergisi. Cilt / Vol: 7, Sayı/lssue: 2, Sayfa: 1124-1138. 